\title{
THE BENEFICIATION OF MUMBWA PHOSPHATE DEPOSIT BY VARIOUS TECHNIQUES
}

\author{
Lukomona, C. ${ }^{1}$, Mwalula, J. B. and Witika, L. K. ${ }^{2}$ \\ ${ }^{1}$ Mopani Copper Mines, Plc, Mufulira. \\ ${ }^{2}$ University of Zambia, School of Mines, Department of Metallurgy and Mineral Processing, \\ P. O Box 32379, Lusaka, Zambia.
}

\begin{abstract}
The Mumbwa phosphate ore constitutes of Apatite(43.6wt\%) as the major mineral, Feldspar(29.0wt\%), Iron oxides(14.4wt\%), minor quantities of Quartz(8wt\%) and the rest being trace minerals. The chemical composition of the ore averages $22.7 \% \mathrm{P}_{2} \mathrm{O}_{5}$ with the other constituents being $22.8 \% \mathrm{SiO}_{2}, 19.0 \% \mathrm{CaO}, 7.0 \% \mathrm{Fe}_{2} \mathrm{O}_{3}, 4.0 \% \mathrm{Al}_{2} \mathrm{O}_{3}$ and $0.2 \% \mathrm{MgO}$. Beneficiation studies were performed to investigate methods of concentrating the phosphate values. Preliminary investigations involved detailed identification of mineralogical and chemical properties of the constituents minerals which would form the basis of selective separation of the phosphate values from the gangue. The results of these studies showed that liberation of apatite occurred below the average grain size of $500 \mu \mathrm{m}$. On the basis of the identified mineralogical and chemical properties of the minerals, heavy media separation using Bromoform and subsequently flotation were applied in the beneficiation tests. The results indicate that heavy media separation techniques could not be used to give a final phosphate concentrate. It has to be a pre-concentration process prior to another concentration process. Encouraging concentrate grades were obtained after flotation with a cationic collector, petroleum sulphonate. The optimum pH being 9.5 and the concentration of petroleum sulphonate $1200 \mathrm{~g} / \mathrm{ton}$. Under these conditions, the grade was $40.8 \% \mathrm{P}_{2} \mathrm{O}_{5}$ with $1.65 \% \mathrm{SiO}_{2}$ while the combined grade was $50.2 \% \mathrm{P}_{2} \mathrm{O}_{5}$. On the basis of this test, a treatment flow sheet for this deposit has been proposed.
\end{abstract}

KEYWORDS: Phosphate, Apatite, beneficiation, heavy media separation, flotation

\section{INTRODUCTION}

The Mumbwa phosphate deposit lies in Sugar Loaf area in the "Big Concession" about $50 \mathrm{~km}$ Northwest of Mumbwa Township and is accessible by a gravel road that runs from Mumbwa to Kasempa.

Mineral Search of Africa PVC Limited first reported the presence of phosphate minerals in Mumbwa in 1958 when it recognised phosphate occurrence with copper mineralisation (Brandt, 1958).

After an extensive soil and rock sampling, reinforced by geological mapping and geophysical survey the presence of pegmatite bodies with high grade $\mathrm{P}_{2} \mathrm{O}_{5}$ were discovered by MINEX (Bwerinofa and Somney, 1977).

The total estimated apatite reserves is about $1.22 \times 10^{6}$ Tonnes at $12 \% \mathrm{P}_{2} \mathrm{O}_{5}$ taking a cut-off grade of $5 \% \mathrm{P}_{2} \mathrm{O}_{5}$.
The phosphate mineralisation occurs in three different types:

1 Apatite associated with copper and iron mineralisation

2. Apatite pegmatite bodies

3. Copper-phosphates in supergene concentrations

The apatite associated with copper and iron occurs with mainly hematite, altered feldspar with subordinate magnetite, pyrite, chalcopyrite and quartz.

The apatite pegmatite bodies comprise of rocks that are almost mono-mineralic with occasional crystals of feldspar. The apatite is hydroxyl apatite and contains high concentrations of atrium, strontium, niobium, uranium and low concentration of zirconium and rubidium. 


\section{LUKOMONA}

The copper phosphate is formed as a result of weathering process of apatite minerals in association with the sulphides ( Mulela, 1991).

At the time the nation is facing serious problems in providing cheap agricultural input, it is important to concentrate on exploiting local raw materials to come up with ways of creating employment for the so many jobless. One way of doing this is to go in ventures that may also benefit the nation by producing products that will be able to compete favourably with imported similar materials. The undoubtedly potential contender for such a challenge is the local produced Partially Acidulated Phosphate Rock (Nkonde et al, 1991; Zambezi and Chipola, 1991; Goma et al, 1991). This realisation would be made possible if the local phosphate ore could be made suitable to achieve this goal. The mostly widely used methods to attain this suitability involve the use of the differences in the physical, chemical and mineralogical properties of the various constituents of the ores.

In a recent review on the beneficiation investigations earlier carried out in the University of Zambia, School of Mines, on various Zambian phosphate ores, it was noted that various processes are unavoidably necessary to compliment each other (Lombe, 1985; Simukanga, 1986; Lukomona, 1989).

In this work, mineralogical, chemical and physical properties of Mumbwa phosphate ore were characterised in order to determine the most appropriate separation method of the phosphate values from various gangue minerals. Electrokinetic measurements were also carried out to establish the electrical double layer properties of the various minerals under different pulp conditions as practised in flotation processes.

\section{EXPERIMENTAL PROCEDURE}

\section{Petrological, Mineralogical and Chemical Analyses}

In order to carry out petrological and mineralogical analyses, several boulders were taken from various trenches of the deposit from which several representative thin sections were made. These were then examined using transmitted light ore microscopic technique. Apart from normal identification of various minerals, point counting was also used to quantify the various minerals and then the grain size estimation was done. After size reduction followed by screening, chemical analyses were done on various fractions to assess the concentration of phosphate grains in various size fractions.

\section{Heavy Media Separation}

Gravity concentration technique was done on different size fractions using Bromoform assess the extent to which phosphate values could be upgraded in each size fraction.

The apparatus used was basically a stationary density separator consisting of mixing, separation and glass filter funnels and a collecting beaker.

\section{Electrokinetic studies}

The surface chemistry of the various mineral species was studied using electrophoresis with the help of a Rank Brothers Mark II micro particle electrophoresis apparatus fitted with CCD Video camera which was connected to a Monitor through an interface. Almost "pure" apatite, quartz, calcite and magnetite grains were isolated from the ore and then ground in a mortar to powder form. These were then used to make suspensions in a $10^{-3} \mathrm{M} \mathrm{NaCl}$ background solution to be used for electrophoretic mobility measurements. The surface charge was determined by converting the mobilities to Zeta potentials using the Smoluchowski equation. A detailed explanation of the principles on which this method is based has fairly recently been summarised by Kyros and Matis, 1995.

\section{Flotation tests.}

Flotation of the ore was carried out using the medium-fine size fraction $75 \mu \mathrm{m}$ to

$212 \mu \mathrm{m}$. This size range coincided with the range in which most of the apatite values were distributed.

A 1 litre normal laboratory Denver bench flotation cell was used for all experiments and Mumbwa ore leach filtrate was used to carry out flotation. The filtrate was obtained by leaching the ore over two nights to simulate the water around the region. The $\mathrm{pH}$ of the bulk solution was maintained constant through the addition of either rock of lime or sulphuric acid. The collector used was Petroleum Sulphonate whilst pine oil was added to stabilise the froth. The conditioning time was kept at 3 minutes while the pulling time was 3 and 2 minutes for the primary and secondary concentrates respectively. The impeller speed was kept constant at $1200 \mathrm{rpm}$. 


\section{RESULTS AND DISCUSSION}

The mineralogical experiments revealed that the apatite grains appeared as distinct white hexagonal prismatic crystals. Under polarised light, the crystal exhibited pleochroism with colour changing from greyish blue to dark grey as the thin section was rotated on the stage. This is a distinctive characteristic of apatite grains.

Quartz appeared as light yellow anhedral crystals that turned bright under polarised light. The main matrix consisted of a light brown phase resembling altered feldspar to ceresite.

XRF scan on the head sample revealed the presence of Calcium, Phosphorus, Silicon and Iron as the major elements with Aluminium and Potassium as minor elements. Trace elements included Manganese, Barium, Zirconium, Cerium, Titanium, Zinc, Strontium and Molybdenum. The main Apatite constituent was identified as Calcium Phosphate Hydroxide( Hydroxyapatite).

The average apatite abundance was $43.6 \mathrm{wt} \%$, while that of the gangue minerals, feldspar and quartz was $29.0 \mathrm{wt} \%$ and $8.0 \mathrm{wt} \%$ respectively and rest being iron minerals, minor and trace minerals. The average abundance of iron minerals was $14.4 \mathrm{wt} \%$ which may warrant the use of magnetic techniques to remove them.

In order to determine the optimum mesh of grind, the grain size measurement was done using the average projected area diameter approach and was estimated as $505 \mu \mathrm{m}$.

After stage crushing and screening, it was established that about $65 \%$ of the material was finer than $300 \mu \mathrm{m}$ of which about $19.4 \%$ went to finest fraction $-53 \mu \mathrm{m}$. This considerable amount of slimes should be first deslimed before any flotation could be conducted.

X-ray Fluorescence (XRF) and Atomic Absorption Spectrophotometry (AAS) of the various size fractions revealed that there was a progressive increase in the $\mathrm{P}_{2} \mathrm{O}_{5}$ grade with reduction in size. Although the estimated grain size was $505 \mu \mathrm{m}$, the enrichment ratios greater than 1 only occurred in the size range $75 \mu \mathrm{m}$ to $300 \mu \mathrm{m}$. This shows that it is not necessarily true to assume that the estimated grain is to correspond to the optimum mesh of grind. It was also established that the $-53 \mu \mathrm{m}$ fraction had the highest distribution of $\mathrm{P}_{2} \mathrm{O}_{5}$ due to the apatite which is finely disseminated in the ore matrix. However, the bulk of the apatite was distributed in the size range $150 \mu \mathrm{m}$ to $212 \mu \mathrm{m}$ that was then used as feed to flotation.
The highest calcite grade was found to be in the range $75 \mu \mathrm{m}$ to $212 \mu \mathrm{m}$ which coincided with the highest enrichment ratios of apatite. This was due to the close association of the apatite mineral with calcite as reflected in the mineralogical analysis.

\section{GRAVITY SEPARATION}

In order to use this separation technique, there must be a substantial difference in the specific gravities of the minerals to be separated and the separating media. The most important criterion is the concentration ratio which should be at least 1.5. This ratio is defined as follows:

$C R=\frac{S_{h}-S_{f}}{S_{l}-S_{f}}$

$S_{h}=$ Specific gravity of the heavy mineral

$S_{f=}$ Specific gravity of the light mineral

$S_{l=}$ Specific gravity of the media

Table 1 shows that there is virtually little difference in the specific gravities of the major gangue minerals calcite, quartz and feldspar. However, it appears that gravity techniques can be used to separate apatite from the rest of the gangue minerals. Since Bromoform has a specific surface intermediate between apatite and gangue, it was suggested that gravity concentration should be tested by laboratory sink-float tests using Bromoform $(\mathrm{S} . \mathrm{G}=2.87$ ) as the separating medium.

Table 1: Specific gravities of the minerals present in bulk in Mumbwa Phosphate Ore

\begin{tabular}{|l|c|}
\hline Mineral & Specific Gravities \\
\hline Apatite & 3.2 \\
Calcite & 2.7 \\
Quartz & 2.6 \\
Feldspar & $2.56-2.76$ \\
Magnetite & 5.17 \\
\hline
\end{tabular}

The results of these studies reveal that very high recoveries can be obtained but with very low enrichment ratios. Theoretically, by using Bromoform with a specific gravity (S.G) of 2.87, and looking at the S.G values of the various constituents, Apatite and Magnetite would report to the "sink". Indeed, the Apatite grade of the sink increased gradually with increase in the particle size. This is due to density differences between the various mineral phases as the particles approach the coarse size range. The larger the size of the particle, the greater is the gravitation pull on it. As a result, in the coarse size range Magnetic Separation can be used to concentrate the phosphate values. 
Mineralogical studies revealed that the ore contains about $4.9 \%$ iron in the form of oxides. Testing with a hand magnet showed that the ore contained some magnetic fraction, most probably magnetite. Due to the presence of large quantities of calcite (19.0\%) and Quartz (22.8\%), magnetic separation can only be done in combination with other beneficiation processes either as a pre-concentration step or as a last step in the beneficiation process.

\section{ELECTROKINETICSTUDIES}

The idea to carry out a surface chemistry study of the various minerals in a given ore is to establish their surface charge characteristics in solution. This then facilitates the selection of the flotation regime to be applied.

Figure 1 shows the surface charges in ordinary University of Zambia(UNZA) water of Quartz, Calcite, Apatite and Magnetite isolated from Mumbwa Surgar-loaf Phosphate ore. Quartz, Apatite and Magnetite had Points of Zero Charge $\left(\mathrm{pH}_{\mathrm{pzc}}\right)$ at $\mathrm{pH}$ values 2.2, 2.8 and 4.7 respectively. However, Calcite showed no charge in the surface charge by remaining negatively charged in the entire $\mathrm{pH}$ range. At $\mathrm{pH}$ around 2.5, Apatite and Magnetite surfaces would both be positively whilst that of Calcite and Quartz will be negative. This follows that theoretically, the use of an anionic collector would adsorb on the surfaces of Apatite and Magnetite through coulombic attraction which will render both minerals hydrophobic and hence floatable in the presence of sufficient air bubbles. The resulting concentrates would then be a mixture of Apatite and Magnetite that could be separated through a wet magnetic separation.

If the beneficiation was to be carried out on site, it would be unavoidable to use a water source which would be in the neighbourhood. This source of water would have properties that will be determined by the surrounding rock. The surface behaviour of the various minerals would be, in a way, influenced by dissolved ionic species in the solution. Hence the surface chemistry of the same minerals was studied using the Mumbwa ore leach filtrate. The results of these studies are shown in figure 2, and shows that the dissolved ionic species have more or less an effect on the surface charge of Quartz. However, the $\mathrm{pH}_{\mathrm{pzc}}$ of Magnetite and Apatite were decreased and increased to $\mathrm{pH}$ values 3.2 and 3.8 respectively. On the other hand, Calcite showed now that it had $\mathrm{pH}_{\mathrm{pzc}}$ at $\mathrm{pH}$ of 4.1.

Calcium ionic species are known to preferentially adsorb on the surface of apatite and may lead to the increased of the $\mathrm{pH}_{\mathbf{p z c}}$ of the mineral. This resulted a decrease in the

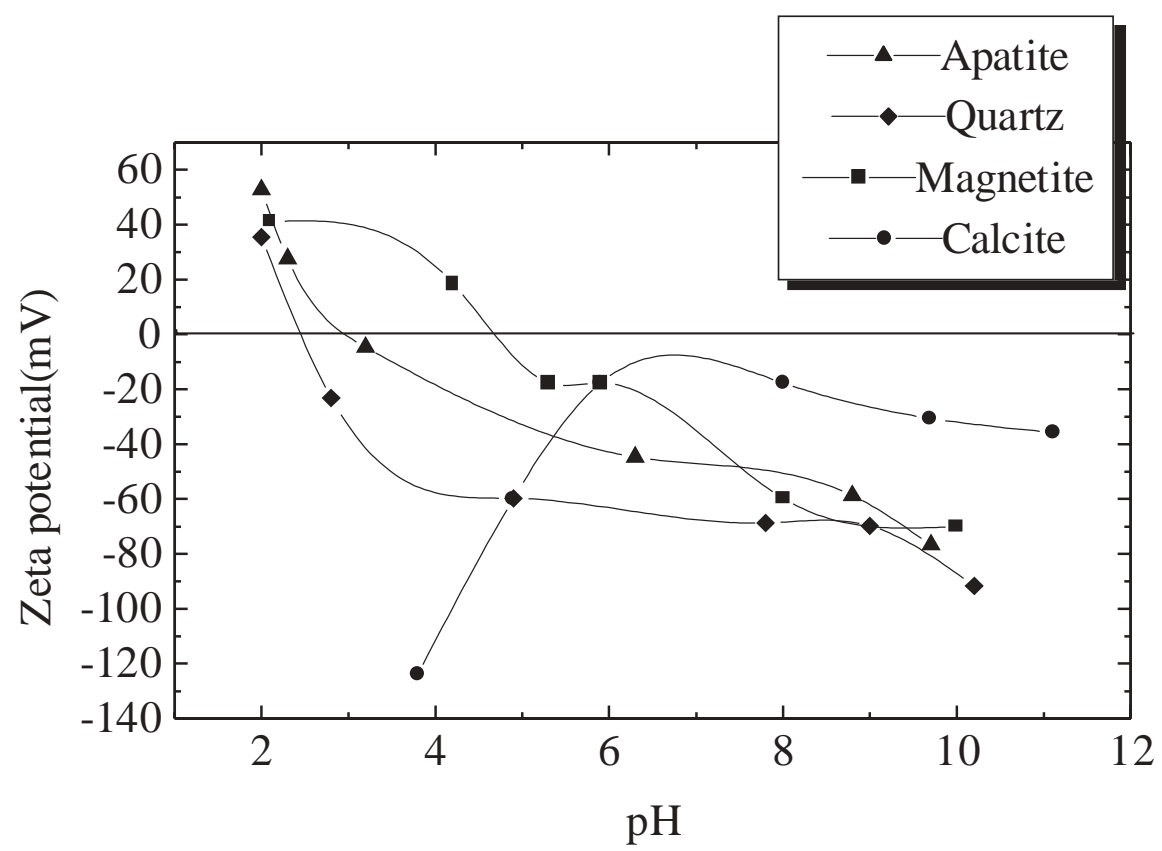

Figure 1: Effect of $\mathrm{pH}$ on the Zeta potential of Apatite, Calcite, Magnetite and Quartz in distilled water at ionic strength of $10^{-3} \mathrm{M} \mathrm{NaCl}$ 


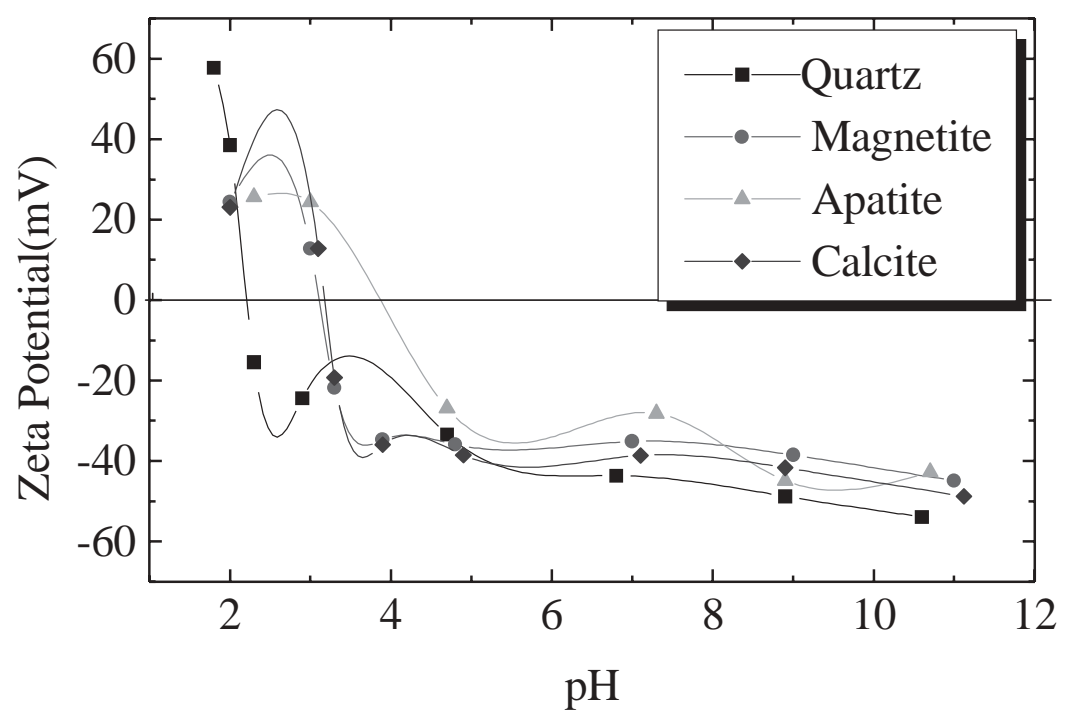

Figure 2: Zeta potential of Quartz, Magnetite, Apatite and Calcite in Mumbwa ore leach filtrate at constant ionic strength of 10-3 M NaCl

magnitude of the negative charge on the mineral. The presence of negatively charged ions such as hydrocarbonate ions may be the reason for the decrease in the magnitude of the surface charge on the Magnetite.

This change of the surface chemistry of the minerals may lead to the assumption that with a short carbon chain anionic collector, which may be specific for Apatite at $\mathrm{pH}$ values above 3.8 , it is possible to float it with some Calcite, which can later be depressed in a cleaning stage.

\section{FLOTATION RESULTS}

\section{Effect of pH on the recovery of $\mathrm{P}_{2} \mathrm{O}_{5}$}

Figure 3 shows the recovery and the grade of the apatite at varying $\mathrm{pH}$ values with a constant concentration of petroleum sulphonate of $900 \mathrm{~g} / \mathrm{t}$. The primary recovery gave two peaks of about $22.5 \% \mathrm{P}_{2} \mathrm{O}_{5}$ at $\mathrm{pH}$ values of 6.5 and 9.5. However, the average grade of $24.8 \% \mathrm{P}_{2} \mathrm{O}_{5}$ was slightly higher at $\mathrm{pH} 9.5$ with a combined recovery of $23.0 \%$ $\mathrm{P}_{2} \mathrm{O}_{5}$. This $\mathrm{pH}$ value was then used to optimise the dosage of the petroleum sulphonate.

Figure 4 shows that the grade of $\mathrm{P}_{2} \mathrm{O}_{5}$ increases steadily with increase in the petroleum sulphonate concentration until it reaches a peak of about $37.0 \% \mathrm{P}_{2} \mathrm{O}_{5}$ at somewhere around $1100 \mathrm{~g} /$ tonne. At low collector concentration, the concentrate grade is relatively lower because not enough collector molecules are available to adsorb on most apatite mineral surfaces to render them sufficiently hydrophobic to report to the froth layer.

The recovery curve shows two distinct peaks at collector concentration of $1200 \mathrm{~g} /$ tonne and $1900 \mathrm{~g} /$ tonne. At these two concentrations, the grades of the primary concentrates are fairly the same. It is just logical to take the lower dosage as the optimum collector concentration due to the cost of the reagent. 


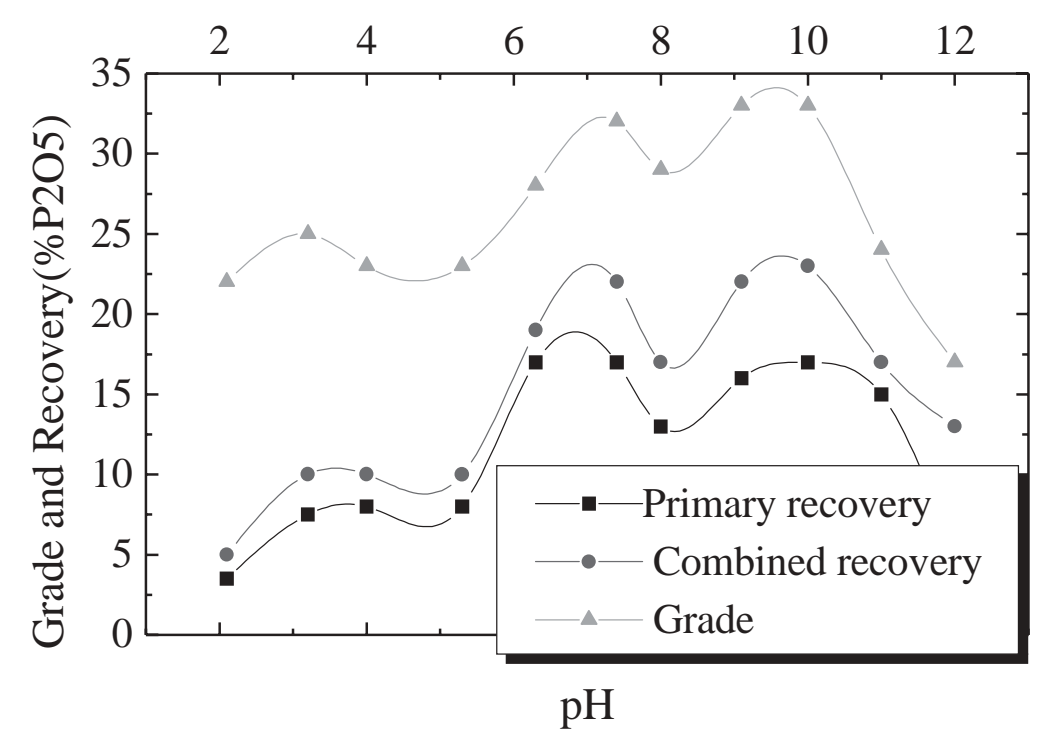

Figure 3: Effect of $\mathrm{pH}$ on the recovery and grade of $\mathrm{P2O5}$ at 900g/t of Petroleum Sulphonate concentration.

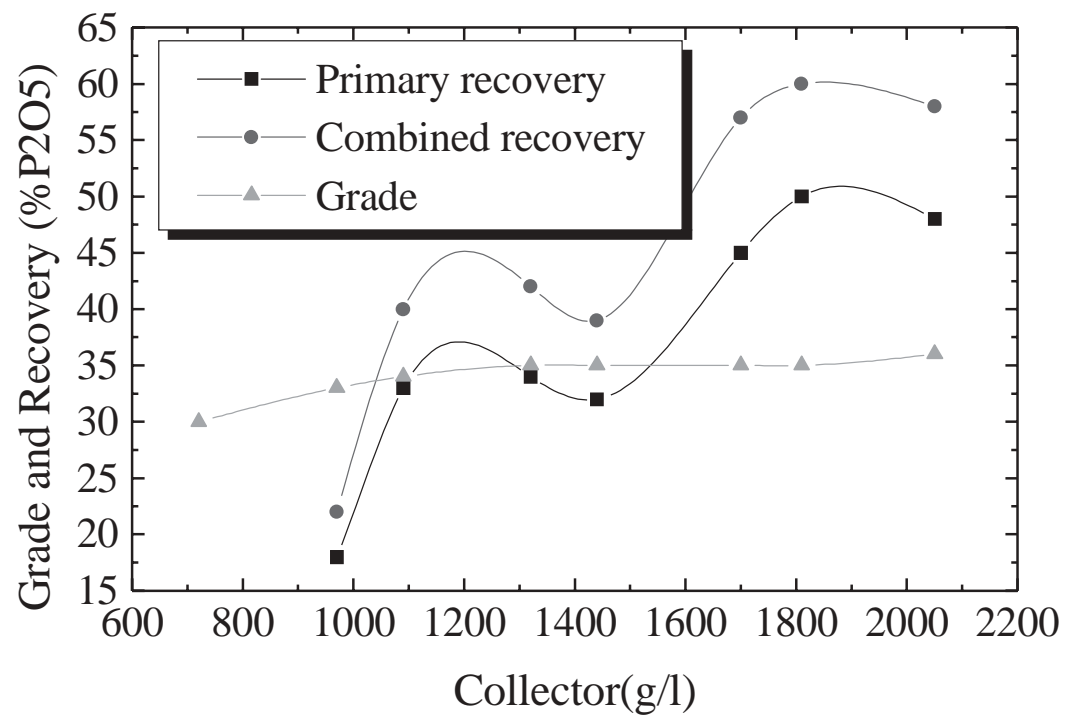

Figure 4: The effect of grade and recovery of $\mathrm{P2O5}$ on the concentration of Petroleum Sulponate at pH 9.5 


\section{CONCLUSIONS}

Preliminary investigations of the Mumbwa Phosphate ore deposit has shown there is a potential of using the heavy media techniques to concentrate the phosphate and magnetite values in a pre-concentration stage. Although Bromoform was used on the laboratory scale, it could not be application on a commercial pilot plant scale due mostly for it's toxicity and expense. A practical solution to this would be to use ferrosilicon or a suspension of fine magnetite

Flotation appears to be the most promising concentration process for the size fraction $212 \mu \mathrm{m}$ to $75 \mu \mathrm{m}$ were the enrichment ratio was significant. Flotation would be effective in an alkaline environment favourable to most equipment. Since most of the iron oxides reported to the tailings, it is advisable to treat them using wet magnetic techniques and subject them to a further flotation to recover the entrained apatite. Alternatively, it is also suggested to try other cationic collectors such as Lilaflot, which was not used due to lack of time.

\section{REFERENCES}

Brandt, D. R.,(1958): The geology and mineral resources of the Big Concession, Mumbwa District. Geological Survey Bulletin No. 2, Lusaka, Zambia.

Bwerinofa, K andSomney, K. Y.,(1977): Kaluwe Carbonatite. P.L 136, Final report, MINDECO Limited, unpublished report.

Mulela, D.,(1991):Igneous phosphates occurrences in Zambia, Proceedings of the Conference on the Utilisation of local phosphate deposits for the benefit of the Zambian Farmer., 9-17 June 1991, p26-38, Siavonga, Zambia.
Goma, H, Phiri, S., Mapiki, A and Singh, B. R., (1991): Production and Economics of Partially Acidulated Phosphate Rock- Implication for Zambia. Proceedings of the Conference on the Utilisation of local phosphate deposits for the benefit of the Zambian Farmer., 9-17 June 1991, p 163-182, Siavonga, Zambia.

Kydros, A and Matis, K. A, (1995): Flotation of iron sulphide minerals: Electrokinetic Aspects. In: Flotation, Science and Engineering. K. A. Matis, Editor. Marcel Dekker, Inc. NY.

Lombe, W. C.,(1985): Process design study for the beneficiation of Chilembwe phosphate ore. School of Mines, University of Zambia, unpublished report.

Lukomona, C., (1989): Process design study for the beneficiation of Mumbwa Sugar-loaf phosphate ore. B. Min. Sc, Project Report, School of Mines, University of Zambia, unpublished report.

Nkonde, G. K., Simukanga, S and Witika, L. K.,(1991): Production of Partially A c i d u l a t e d Phosphate Rock (PAPR) from Chilembwe Ore at the University of Zambia. Proceedings of the Conference on the Utilisation of local phosphate deposits for the benefit of the Zambian Farmer., 9-17 June 1991, p63-73, Siavonga, Zambia.

Simukanga, S.,(1986): Process design study for the beneficiation of Kaluwe Phosphate ore.

MMin.Sc. Dissertation, University of Zambia, unpublished report.

Zambezi, P. and Chipola, P., (1991): Production of Partially Acidulated Phosphate Rock ( P A P R ) f r o m Chilembwe Ore at MINEX department of ZIMCO, Proceedings of the Conference on theUtilisation of local phosphate deposits for the benefit of the Zambian Farmer., 9-17 June 1991,p57-62, Siavonga, Zambia. 